\title{
Leren in de praktijk
}

\section{EREN IN DE PRAKTIJK WORDT}

steeds belangrijker, zowel voor stu-

denten van initiële opleidingen als voor verpleegkundigen die al werkzaam zijn en zich in een traject van levenslang ontwikkelen bevinden. Er worden nieuwe behandelingen en benaderingsmethoden ontwikkeld. Tegelijkertijd is het belangrijk verpleegkundigen meer zeggenschap te geven over de inrichting van hun leertraject, dat past bij hun situatie en mogelijkheden.

We besteden aandacht aan drie praktijkvoorbeelden van leren in de praktijk van het ziekenhuis, met drie invalshoeken. Ten eerste een nieuwe behandelmethode (celtherapie) in het Antoni van Leeuwenhoek die nieuwe kennis vereist van verpleegkundigen die deze patiënten verplegen. Deze kennis is binnen korte termijn in een e-learning omgezet. Verder laat de leerhuismanager van het Deventer Ziekenhuis zien hoe de organisatie vorm geeft aan de verantwoordelijkheid van verpleegkundigen bij het actueel houden van hun bekwaamheid op het gebied van voorbehouden handelingen op een manier die past bij de afdeling. Het voorschrijven van een vast leertraject met controle is losgelaten. Ten slotte komt leerhuismanager Wilma Jackson van het ElisabethTweeSteden Ziekenhuis aan het woord. Zij gaat in op (problemen met) leren in de context van Covid-19 en geeft aan hoe belangrijk het is dat een ziekenhuis aandacht blijft besteden aan een vruchtbaar opleidingsklimaat. Even belangrijk als patientenzorg, met de bedoeling die zorg ook in de toekomst te kunnen blijven aanbieden op kwalitatief goed niveau.

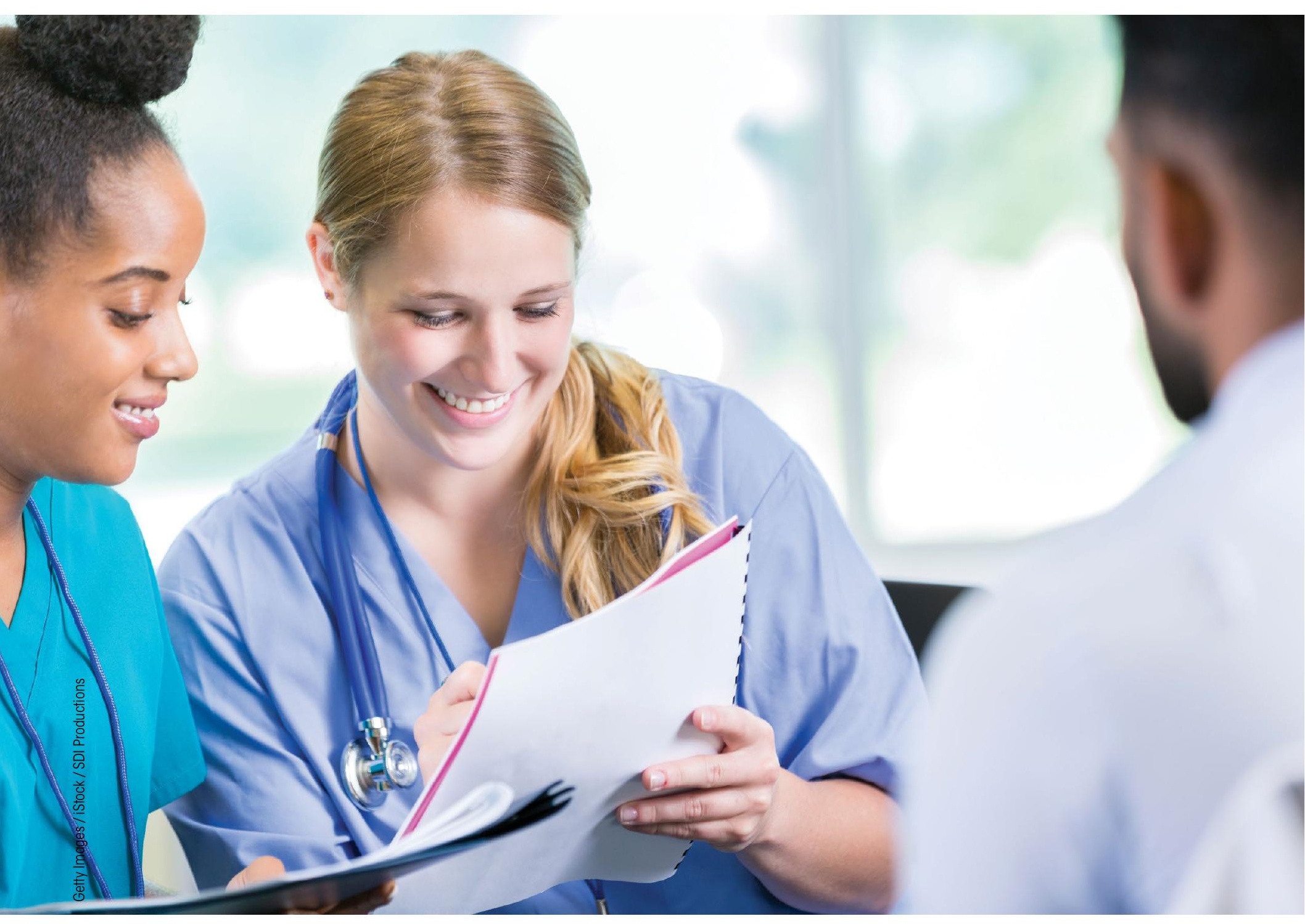




\section{E-learning voor verpleegkundigen}

In het Antoni van Leeuwenhoek (AVL) loopt een veelbelovende studie naar celtherapie. Dit is een vrij nieuwe, zeer complexe kankerbehandeling. Om de verpleegkundigen die met de patiënten werken te ondersteunen, werd een e-learning ontwikkeld.

door Sigrid Starremans

$\mathrm{H}$ ET GAAT OM EEN VAN DE EERste klinische studies naar celtherapie in Europa. 'Als zo'n studie succesvol is, dan zetten we een grote stap in de behandeling van kanker,' vertelt John Haanen, internist-oncoloog en medisch clusterhoofd van de Medisch Oncologische Disciplines bij het Antoni van Leeuwenhoek. 'Deze studies zijn enorm belangrijk.'

\section{Spannend}

Niet alleen onderzoekers, ook het verpleegkundig personeel speelt een cruciale rol bij het goed laten verlopen van het onderzoek. Juist omdat celtherapie nog vrij nieuw is en een andere toxiciteit heeft, kunnen zich onverwachte situaties voordoen. Bijvoorbeeld als het gaat om bijwerkingen van de behandeling. 'En dat maakt het spannend voor de verpleegkundigen', vervolgt Haanen. 'Hoe ga je om met die onzekerheid? Het gedrag van het verplegend personeel is erg belangrijk in dit soort situaties. Ook als het gaat om het nauwkeurig volgen van protocollen en het documenteren van ontwikkelingen. Het vergroten van zelfvertrouwen begint met het verhogen van het kennisniveau.'

\section{Snelle actie}

Dat er naast scenariotrainingen ook een e-learning moest komen, was evident en werd gedragen door de hele organisatie. Miriam Boer, manager AVL Academie, nam contact op met Bohn Stafleu van Loghum (BSL) voor de ontwikkeling van een e-learning voor verpleegkundigen die met de desbetreffende patiënten werken. De e-learning werd in een maand tijd gemaakt en opgeleverd.

\section{Veel betrokkenheid}

Met behulp van de Hofsteestichting en de raad van bestuur kwam er extra funding voor onderwijs over celtherapie. Managers lazen in hun weekend stukken door en zorgden ervoor dat dit traject in snel tempo ontwikkeld kon worden. Ook heel bijzonder was dat Haanen bij de brainstormsessies over de e-learning aanwezig was. Het is niet vanzelfsprekend dat een onderzoeker en arts zo nauw betrokken is bij dit proces. 'Zijn aanwezigheid heeft alle betrokkenen doordrongen van het belang van de ontwikkeling van de e-learning', vertelt Boer. 'Dat werd door de zorgverleners enorm gewaardeerd,'

\section{Bijdrage verpleegkundigen}

Voor BSL was de medewerking van de inhoudsdeskundigen erg belangrijk. Ook omdat het om nieuwe, pittige, complexe materie gaat die voor een groot deel nog niet te vinden is in medische bibliotheken. Zonder de intensieve samenwerking met onderzoekers, verpleegkundigen en het leerhuis had de e-learning nooit in zo'n kort tijdsbestek ontwikkeld kunnen worden. De onderzoekers en een gespecialiseerd verpleegkundige schreven stukken voor de e-learning over hun specialisme in relatie tot de studie. Voor de verpleegkundige was dit nog best een uitdaging. Vanwege Covid-19 kon niet altijd tijd vrijgemaakt worden, maar het AVL zocht naar oplossingen. Het kwam weleens voor dat het gunstigste moment voor samenwerking tijdens de nachtdienst was. Dus hingen de opleidingsadviseur en de leerhuismanager om 23.00 uur aan de telefoon met de verpleegkundige om vragen te stellen over de inhoud van het werk en dit goed te vertalen in de e-learning.

\section{Continu updaten}

Uiteindelijk lag binnen vier weken een hoogwaardige e-learning op de plank. Een interactief geheel waarin behalve tekst ook video's, afbeeldingen, spraakberichten en infographics zijn opgenomen. Boer: 'Belangrijk is dat we de e-learning continu kunnen blijven voor-

\section{'Het vergroten van zelfvertrouwen begint met het verhogen van het kennisniveau'}

zien van updates. Dat is met boeken niet te doen. De ontwikkelingen gaan, zeker op dit terrein, supersnel.'

\section{Voorop lopen}

'Waar je naartoe wilt is een afdeling die zo goed functioneert, dat we het good clinical practice kunnen noemen', zegt Haanen. Door nu al een e-learning voor celtherapie te ontwikkelen en er zwaar op in te zetten, loopt het AVL voorop in het veld, vindt hij. 'En dat is ook wat we willen, een voorloper en een toonaangevend centrum zijn. Niet alleen als het gaat om de behandeling. We nemen ook andere aspecten die daarbij een rol spelen in ogenschouw. Zoals een heel goed leerprogramma. Zodat ook anderen daar gebruik van kunnen maken.' 


\section{Meer eigen regie}

Werkplek-en gepersonaliseerd leren, meer eigen regie. Het zijn inmiddels bekende begrippen in de ziekenhuiswereld. Het Deventer Ziekenhuis heeft grote ambities op dit vlak. Een aantal jaar geleden werd een veranderingsproces in gang gezet. Medewerkers beslissen nu onder meer zelf hoe ze hun herregistratie aanpakken.

door Sigrid Starremans

M OET EEN VERPLEEGKUNDIGE die dagelijks een risicovolle handeling verricht om de zoveel tijd verplicht een hele e-learning doornemen en een toets doen om zich opnieuw te laten registreren? Waarom zijn er zulke uitgebreide competentieprofielen? Medewerkers moeten eraan voldoen, maar ze passen niet altijd voldoende bij de afdeling en de functie. Deze geluiden waren regelmatig te horen in het Deventer Ziekenhuis.

\section{Leren op eigen manier}

De adviseurs van het Teaching Hospital Deventer pikten de signalen op en gingen ermee aan de slag. We besloten om onze visie op leren aan te scherpen', vertelt José Geerdink, leerhuismanager. 'Vragen daarbij waren onder andere: wat vinden we nu als onderwijsexperts belangrijk als het om leren gaat? Maar ook: wat vinden de medewerkers belangriik?'

Geconcludeerd werd dat leren zinvoller en betekenisvoller moet worden. En dat medewerkers meer eigen regie en verantwoordelijkheid zouden moeten krijgen. Iedereen zou moeten kunnen leren op zijn eigen manier. Dat betekent ook het loslaten van controle en het creëren van meer vertrouwen in de medewerkers. 'Daarmee sluiten we aan bij de grote thema's die op dit moment in de zorg spelen', vervolgt Geerdink. 'Heb je het bijvoorbeeld over verpleegkundig leiderschap, een onderwerp waar nu veel over gesproken wordt, dan doe je ook een groter beroep op de eigen regie en professionaliteit van medewerkers. Dat stuk willen we ook meer inbrengen rondom het thema leren en ontwikke- len.' Lianne Ilsink, adviseur leren en ontwikkelen, vult aan: 'Uit wetenschappelijk onderzoek blijkt ook dat meer autonomie bijdraagt aan een hogere motivatie om te leren.'

\section{Ziekenhuisbreed}

Verschillende ziekenhuizen hebben vandaag de dag aandacht voor onderwerpen als werkplekleren en het geven van meer regie aan de medewerkers. Het Deventer Ziekenhuis meent een van de eerste te zijn die hiermee startten, in 2017-2018. Bovendien zijn de ambities groot. Uiteindelijk werd een hele cultuurverandering in gang gezet die verder strekt dan alleen leren en registreren.

Bijzonder is dat dit veranderingsproces ziekenhuisbreed wordt uitgevoerd en alle medewerkers vanaf het begin meegenomen zijn in het proces. 'We hebben gesproken met de staf, de managers en de medewerkers op de werkvloer', vertelt Ilsink. ‘Er zijn vier pilotafdelingen die als ambassadeur fungeren en input leveren voor de verdere ontwikkeling en implementatie van de visie. Ook zijn er informatiebijeenkomsten gehouden en flyers gemaakt. Iedereen heeft zijn zegje kunnen doen, zodat het project breed gedragen wordt.'

\section{Inspectie en NIAZ}

Een van de concrete resultaten van het project is dat het leermanagementsysteem is aangepast en de voorwaardelijkheid uit de leerpaden van de herregistratie gehaald. Medewerkers beslissen nu zelf hoe ze hun herregistratie aanpakken om hun bekwaamheid aan te tonen. Of ze de hele e-learning doornemen, een filmpje kijken, de toets doen, een collega laten meekijken of een zelfbeoordeling geven. 'Dat is spannend voor managers, maar ook medewerkers hadden daar vragen over,' licht Ilsink toe. 'Ze vroegen zich onder andere af of dat zomaar mag van instanties als de Inspectie en het NIAZ. We hebben het gesprek daarover gevoerd met deze instellingen. En dan blijkt er meer mogelijk te zijn dan je wellicht zou denken. Bovendien zegt een officiële toetsing ook niet zoveel', vervolgt ze. 'Medewerkers kunnen een bepaalde handeling tijdens een toetsing volgens protocol uitvoeren, maar het tijdens hun werk op hun eigen manier doen. Wat wij graag zien, is dat er meer overlegd wordt met

\section{'ledereen zou moeten kunnen leren op zijn eigen manier'}

collega's en er een cultuur ontstaat waarin medewerkers elkaar feedback kunnen en durven geven en erover in gesprek gaan met hun manager.'

\section{Learning Experience Platform}

Het project is nog steeds in volle gang. Competentie- en functieprofielen op de verschillende afdelingen worden doorgelicht en bekeken wordt waar aanpassingen nodig zijn. Ook wordt nagegaan hoe de medewerkers op de afdelingen tegen het project aankijken en wat er waar nodig is om het te laten slagen.

Verder staat het ziekenhuis aan de vooravond van de lancering van een Learning eXperience Platform (LXP), een unicum in de ziekenhuiswereld. 'We hebben registratie en leren uit elkaar gehaald', licht Ilsink toe. 'Het LXP moet je zien als een soort Netflix, waar gepersonaliseerde content veel meer naar je toe komt. Denk aan expertisegroepen die informatie delen over het geven van intervisie. Het platform heeft ook een sociale functie. Je kunt er met elkaar in gesprek gaan, je eigen content er opzetten en artikelen met elkaar delen. Het doel is om veel meer met en van elkaar te leren.' 


\section{Opleiden in crisistijd}

Het Elisabeth-TweeSteden Ziekenhuis werd in de eerste en de tweede golf overspoeld met coronapatiënten. Ook opleidingstrajecten kwamen daardoor in de knel. Toch ziet leerhuismanager Wilma Jackson dat de crisis ook tot waardevolle inzichten heeft geleid. 'Het is nu in elk geval duidelijk geworden dat we er alles aan moeten doen om zoveel mogelijk verpleegkundigen op te leiden.'

door Sigrid Starremans

Z O'N 700 STUDENTEN VERPLEEGkunde en eenzelfde aantal co-assistenten lopen ieder jaar stage in het Elisabeth-TweeSteden Ziekenhuis (ETZ) in Tilburg. Verder worden er jaarlijks 125 arts-assistenten opgeleid en vervolgopleidingen gegeven voor verpleegkundigen en de medisch ondersteunende beroepen. Leerhuismanager Wilma Jackson, ooit zelf verpleegkundige, neemt de opleidingstaak van het ziekenhuis uiterst serieus. Haar visie is dat het opleiden van zorgprofessionals net zo belangrijk is als de patiëntenzorg.

\section{Goed toegerust}

'Beroepen als arts en verpleegkundige moet je in de praktijk leren', licht ze toe. 'Zorginstellingen hebben een maatschappelijke verantwoordelijkheid op dat vlak. Als zorgorganisatie kun je niet zeggen: "We gaan volgend jaar verbouwen, of we zitten in een fusie, dus we willen even wat minder stagiaires." En dat is wel wat er gebeurt. Aan de andere kant kun je ook niet zeggen: "Op die afdeling zijn veel zieken, dus daar plaatsen we veel stagiaires." De directie van een zorgorganisatie moet ervoor zorgen dat de mensen op de afdelingen goed toegerust zijn om studenten te begeleiden. En dat is niet mogelijk in een dergelijke situatie.'

\section{Opleidingen onder druk}

Behalve leerhuismanager in het ETZ is Jackson bestuurslid van Profportaal Zorg, een samenwerkingsverband van zorgorganisaties waarbij bronnen en kennis op het gebied van leren en innoveren worden uitgewisseld. Via onder meer deze functie draagt ze haar visie breed uit.
Juist het ETZ werd vorig jaar extra op de proef gesteld. Het ziekenhuis werd hard getroffen door de coronacrisis. Ook de opleidingen kwamen daardoor fors onder druk te staan. Jackson: 'Het was een chaos, het hele ziekenhuis kwam tot stilstand. Alle structuren vielen weg.' Afdelingen werden gesloten. Het was alle hens aan dek op de Covid-19-afdelingen. Dat betekende ook dat studenten niet meer optimaal begeleid konden worden. De medewerkers van het leerhuis moesten, net als het medisch personeel, alle reguliere werkzaamheden uit hun handen laten vallen en zich richten op het managen van de crisis.

\section{In groepjes verdeeld}

De eerste- en tweedejaarsstudenten van de verpleegkundige opleidingen en de co-assistenten werden naar huis gestuurd. 'We wisten niet wat er op ons afkwam', licht Jackson toe. 'Bovendien wilden de opleidingen, en ook vele ouders, de studenten niet aan mogelijke risico's blootstellen.' De derde- en vierdejaarsstudenten verpleegkunde konden wel blijven. Ook omdat ze nodig waren voor de patiëntenzorg. Ze werden in groepjes van twee of drie herverdeeld over de afdelingen, zodat ze steun aan elkaar hadden en nooit alleen zouden komen te staan. Verder lagen alle trainingen voor de zittende medewerkers stil. Het lukte wel om de interne vervolgopleidingen, zoals de opleiding IC-verpleegkundige en operatie-assistent, door te laten gaan. 'Veel is digitaal gegaan', verklaart Jackson. 'In de tweede en derde golf hebben we ook het praktijkonderwijs in de lucht kunnen houden. Al was dat niet altijd even makkelijk.'

\section{Vertraging en achterstand}

Uiteindelijk hebben vooral de vierdejaarsstudenten verpleegkunde en de arts-assistenten van de snijdende vakken vertraging opgelopen vanwege de crisis, vertelt Jackson. 'Sommigen hebben verlenging moeten aanvragen voor hun studie. Met name de studenten verpleegkunde die in mei 2020 afstudeerden, hebben hier last van gehad.

De opleidingen zijn nu weer op het normale peil. Maar er is wel flinke achterstand ontstaan in de basistrainingen, denk aan reanimatie en trauma, voor de interne medewerkers. Jackson verwacht dat de inhaalslag na de zomer van 2021 gemaakt kan worden. 'En dat betekent meer druk op de zorg vanwege de afwezigheid van personeel. We zullen daar extra medewerkers voor moeten inzetten.'

\section{Interessante leeropbrengst}

Voor een antwoord op de vraag of de crisis blijvende effecten heeft op het opleiden, vindt Jackson het nog te vroeg. 'Daar kunnen we pas iets over zeggen als we langere tijd in rustiger vaarwater zitten.'

Wel ziet ze toegevoegde waarde in het gebruik van Teams en de mobiele telefoon. 'Daar hebben we in de crisistijd snel instructiefilmpjes mee kunnen maken. Van hoe je zuurstofmaskers en het EPD gebruikt tot hoe je met besmet materiaal omgaat. Qua leeropbrengsten vind ik dat heel interessant.'

\section{Uitdaging ziekenhuizen}

Ook gaf de crisis Jackson een wrang steuntje in de rug als het gaat om de roep om meer op te leiden. 'Het is nu in elk geval duidelijk geworden dat we er alles aan moeten doen om zoveel mogelijk verpleegkundigen op te leiden', vervolgt ze. 'De uitdaging voor de ziekenhuizen is nu om ruimte te geven aan andere begeleidingsstructuren, zoals een ZIC/ Leerunit waarmee medewerkers patiëntenzorg kunnen bieden én tijd hebben om studenten te begeleiden. Ook moeten we de verpleegkundige populatie flexibeler maken, zodat je in tijden van crisis makkelijker kunt opschalen. Daar zijn al ideeën over die we in de komende tijd gaan uitwerken.' 